\title{
Historical and cultural landscape of the Kuda River valley and its use for recreational purposes
}

\author{
Natalia Shestopalova ${ }^{1, *}$ \\ ${ }^{1}$ Irkutsk National Research Technical University, 664074, Lermontova str., 83, Irkutsk, Russia
}

\begin{abstract}
The issues of the micro-agglomeration organization of the oldest rural settlements of the $18^{\text {th }}$ century in the Irkutsk region, the villages of UstKuda, Urik and Khomutovo, are considered in this paper on the basis of the recreational development, and development of the existing historical and cultural landscapes. The main idea of the research (carried out at the Department of Architecture and Urban Development of Irkutsk National Research Technical University under the guidance of the author), in which the town planning potential of the site was identified and the project proposal followed, as presented in the illustrative part of the article, was transformation of the main axis of the inter-village highway on the Greenway principle: creation of the "Green corridor", saturated with the objects of the tourist cluster (monuments of architecture and natural attractions, panoramic views, etc.), pedestrian alleys, bike paths and other sports and recreational facilities. This will significantly improve the recreational, cultural and, as a result, investment attractiveness of this territory, both for the local population, and for domestic and foreign tourists.
\end{abstract}

The research has been carried out in the framework of the discipline "Historical and cultural landscapes, their preservation and development", studied at the Department of Architecture and Urban Planning with the students of the urban planning specialty (magistracy). The subject of the research was the territory of historical settlements along the Kuda River in the Irkutsk district. The purpose of this study was the use of the historical and cultural potential of the territory for the development of recreation.

Representativeness of the Kuda River landscapes and their historical saturation with the associative features, the availability of the material artefacts - historical and cultural heritage sites - all these factors allowed considering this territory, including historical settlements, as an object in the framework of the tourist cluster.

As a result of the research and design studies, one of the vectors, so-called "greenway", has been proposed for the development of historical and cultural heritage of the territory. Greenway as an outlined element of the urban landscapes appeared in the last quarter of the $20^{\text {th }}$ century.

The principle of organization of spatial environment by the type of greenways was widely used in the USA, where similar structures were created, for example, in the urban

${ }^{*}$ Corresponding author: palchnb2009@ ya.ru 
agglomeration of Raleigh Chapel Hill in early 1970s. Philosophical ideas that underline the purpose and organization of the greenways date back to the second half of the $19^{\text {th }}$ century, to Frederick Lowe Olmsted, the founder of modern landscape architecture of America.

Today, the strategy of using greenway is considered by the international community as one of the directions of territorial development with specific recreational resources. In our case, it is considered in connection with the use of valuable historical and cultural landscapes in accordance with the axiological approach (axiology studies problems related to the nature of values, their place in reality and the structure of the value world, that is, links between different values, and their connection with social and cultural factors and personal perception). [11]

An important aspect of the greenway is its environmental significance. In 2008, the architect A.A. Lyapin was the first one who raised the issue of creating a tourist-health trailgreenway in the Angara region [9, c.59]. Expanding the features of the greenways, A.A. Lyapin notes: "The fundamental difference between a greenway and a simple bike path is more attention to the natural basis of the route. Greenway is not only a path, but also a strip of greening along it, the task of which is to be the basis of aesthetic enjoyment of nature for people during the journey, to be a refuge for animals and birds, and to purify and refresh the air in the cities" [10, p.103]. In case the greenway path is created near, or along the river, the river can become an integral element of it. Walking trails on the land can be supplemented with water routes for kayaks, fishing or rafting. Then the hiking and health trail is complemented by facilities related to water sports - ramps for launching boats, access roads by the water, and berths.

In a broader view of greenway, it should be considered how green routes can be saturated with additional functions, included into the recreation, attracting visitors to the natural and cultural heritage, passing along natural ecological corridors, rivers, historical trade routes, old railways, and historical settlements.

Such routes can be of various lengths, like beads planting tourist attractions on the main communication axis.

Such a form of tourism and recreation is favorable for the environment, promoting a healthy lifestyle and non-motorized forms of movement: cycling, hiking, horseback riding, water tourism, etc.

At the same time, opportunities are being created to improve living standards and the state of the environment, revitalize local economy, promote regional products and develop entrepreneurship among rural people, and also preserve unique natural, landscape and cultural values.

Kuda is the river with the length of $226 \mathrm{~km}$, the right tributary of the Angara River, flowing twenty kilometers from Irkutsk downstream. In the $18^{\text {th }}-19^{\text {th }}$ centuries, in the valley of this river, a system of peasant settlements was formed, consisting of large and small villages. The villages of Khomutovo, Urik and Ust-Kuda occupy the major place in this valley. Urik, founded in 1673, is the oldest of the peasant settlements in the Irkutsk region that survived so far. In the villages of Urik and Ust-Kuda, large stone churches, and a large number of traditional Siberian peasant houses, whose inhabitants currently conduct subsistence farming, preserved to nowadays. Historical buildings were examined, and some of them were placed under the state protection as monuments of architecture. These two villages on the Kuda River, Urik and Ust-Kuda, are monuments of peasant town planning culture, which are of national importance. Historically, these villages were used as a place of mass settlements of exiles, who came here by families and, having served sentences, stayed in Siberia forever, having attributed themselves to the peasant class. Especially many settlers appeared here after the Polish uprising of 1830-1831, in 1863, and after the revolution of 1905. 
Careful and profound study of the architectural and historical heritage of the villages in the valley of the Kuda River began in 1980s. Scientific research was carried out by the Regional Research Laboratory of the Architectural Heritage (RNILAN), on the basis of the Department of History of Architecture and Design of the Irkutsk National Research Technical University (at that time - Irkutsk Polytechnic Institute) under the guidance of the architect and art historian Valery Shcherbin. The task of this laboratory was to inventory and study the architectural heritage of the Eastern Siberia. [8]

The village of Urik is one of the oldest villages in the southern Angara region, overstepping the boundary of its 330-year existence. It arose shortly after the founding of the Irkutsk Ostrog as a settlement of the plowing peasants. The first mention of it refers to the year 1673, when land was given to the "new-sent" people for the first time [1]. Since the first years of its foundation, Urik has been the center of agriculture of the Irkutsk district.

Usual Siberian village, it has forever entered the history of Russia as a place of settlement of the most prominent representatives of Decembrism. Here, in 1836, after hard labor in the Petrovskii casemate, were settled M.S. Lunin, S.G. Volkonsky with his family, brothers N.M. and A.M. Muravyov, F.B. Wolf. Later N.A. Panov joined them. [3]

In Urik, there is a Church of the Savior of the Holy Image 1775-1779 (1796?) [6]. In its architectural appearance, it is very close to the Kharlampiev Church (Figure 1), built in Irkutsk around the same time. The activities of the Decembrists in exile were closely connected with the fate of this temple, in the fence of which is the grave of the Decembrist Nikita Muravyov, one of the leaders of the Northern Society and the author of the draft constitution. The community of believers was registered in the mid-2000s, and the church is currently being restored.

Baroque motifs with receptions and forms of ancient Russian architecture give this temple a specific uniqueness.

In general, the flat nature of the picturesque terrain favorably distinguishes the church as a significant harmonious dominant, which designated the spatial center of the settlement and is organically inscribed in the landscape environment.

The village of Ust-Kuda is the oldest settlement, mentioned already in the 1660 s as a "hub of servicemen" [2], called "Kazachiia Sloboda". It is located on the right bank of the Angara River. In 1679, a settlement Kudinskaia appeared on the banks of the Kuda River. "The place was chosen comfortable and rare in beauty. People willingly began to settle here" [2], and already in 1672 there were 12 households of peasants in Kudinskaia (Krasnaia Sloboda).

In the history of Russia, the village of Ust-Kuda is known for the fact that at about the same time, the participants of the Polish uprising of 1830-1831 Julian Sabinsky and Gaevsky, exiled to Siberia, and the Decembrists who arrived at the settlement, A.V. and I.V. Poggio brothers, P.A. Mukhanov and A.N. Sutgof lived there. The Volkonskys and the Trubetskoys also visited this place with their families [3].

The Church of the Kazan Icon of the Virgin (1803-1807) [6] was built in the unique original plexus of two stylistic trends - the provincially conservative Baroque, and Classicism that only started spreading along the Irkutsk uyezds (Figure 2). At the Soviet epoch, it was abandoned, destroyed, susceptible to fire, and restored in its former look after 2003. 

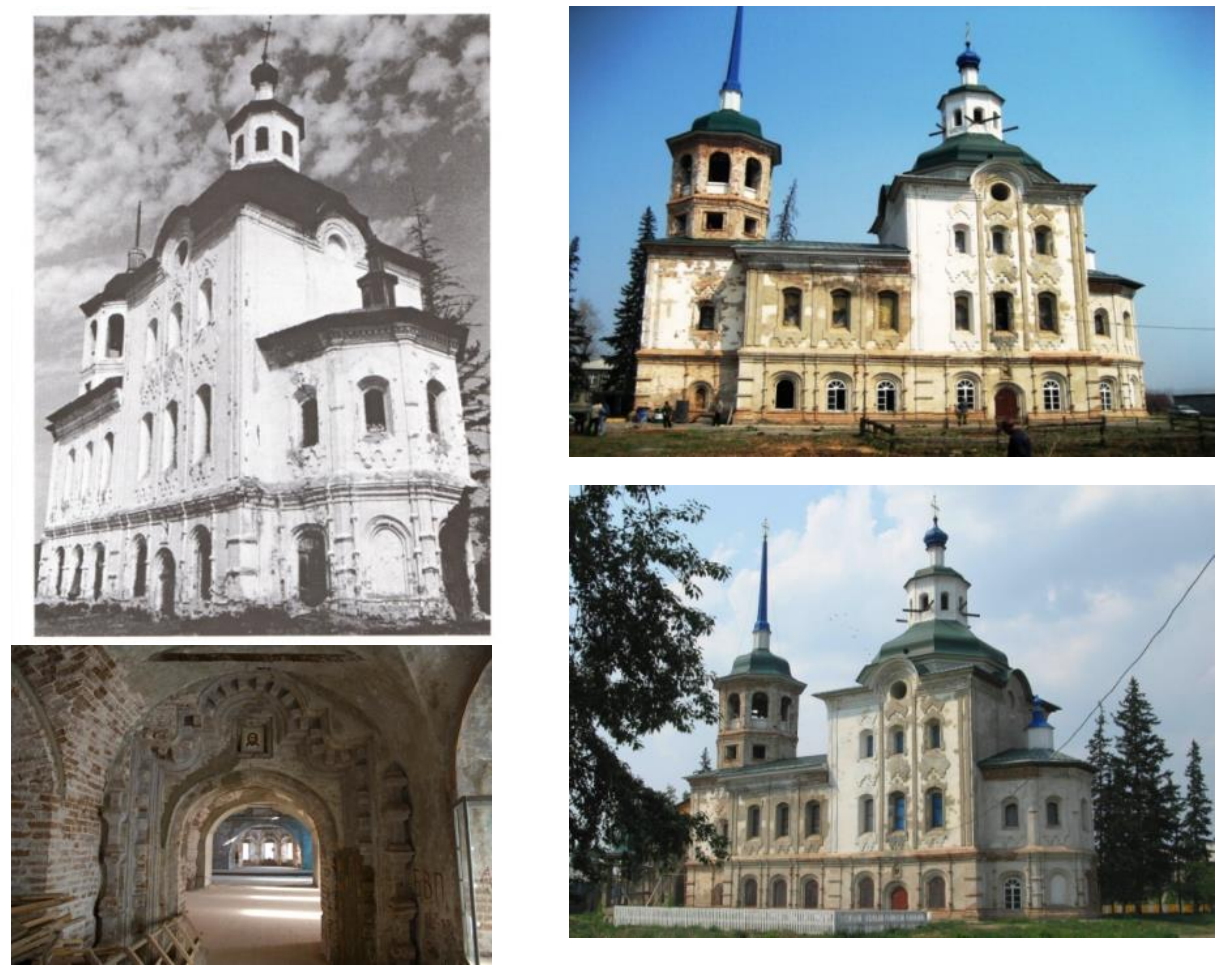

Fig. 1. Village of Urik, the Church of the Savior of the Holy Image.
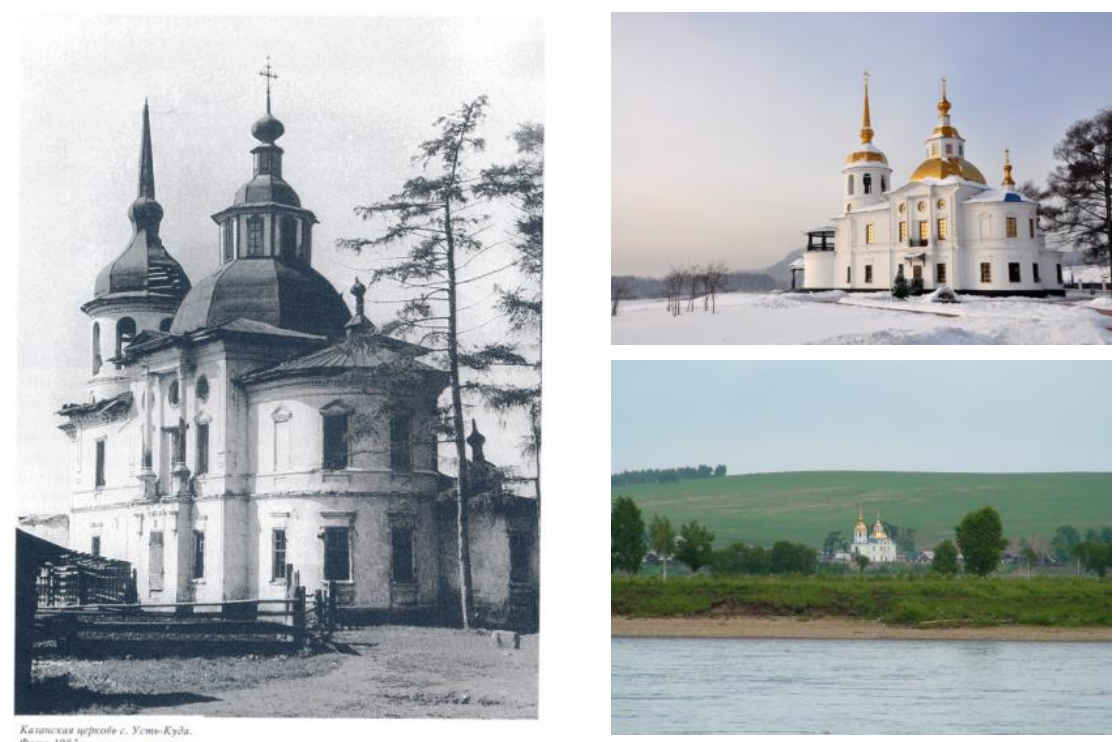

Fig. 2. Village of Ust-Kuda, the Church of the Kazan Icon of the Virgin.

The main idea of the study, undertaken under the guidance of N.V. Shestopalova at the Department of Architecture and Urban Planning, and of the project developed on its basis, is 
the following: taking into account the unique historical and cultural potential of the territory and the peculiar location of spatial formations, as well as historically stable inter-settlement transport and pedestrian links, to use these factors in the recreational development of the territory. Health and educational tourism is seen as the main type of the proposed environmental use of this territory. As additional types of the outdoor activities, the citizens and local residents are offered cycling, walking with sticks, jogging and long walks. The youth can be interested in skating, roller skating, and rock climbing. In addition (in development) to these functions, it is possible to offer enthusiastic thematic excursions with the introduction (organization) of the thematic "loops".

Analogically with the already available experience, eco-museums, which are always based on the idea of drawing attention to a place, are to become focal points of the "loops". Nature, culture and history are studied "on the spot", and the main activities take place with the involvement of the local population through stories, documents, attractions, monuments, etc. The museum exhibits can be picturesque landscapes, unusual plants and animals, villages, houses built in the traditional style, old mansions and estates, elements of a homestead farm, churches and roadside chapels.

In the system of value categories of UNESCO, the landscapes along the Kuda River can be attributed to the agricultural ones in terms of their historical function and to the peasant landscapes by the type of culture. By the degree of cultural transformation, they refer to associative, with the fragments of the evolved and man-made ones. The few remaining foci of traditional folk culture (crafts, handicrafts, and oral folk art) are considered as a part of the naturally formed rural evolved landscapes.

In this context, one can add the following to valuable recreational resources in the study area:

- The natural component of the cultural landscapes: the natural environment, mastered (structured) according to the principles of the Russian peasant landscape as rural community settlements on the basis of subsidiary trades.

- The social component of the cultural landscape is presented by the peasant landscapes with unique (characteristic) spatial organization of the Siberian settlements on the principle of the rural community

- Historical component: historical facts related to outstanding personalities and their activities, reflecting significant milestones of historical development of our state.

- Memorial component: the continuing phenomenon of the "memory of the place" manifested in the semantic saturation of the cultural landscape with historical associations connected with historical personalities and events; legends, historical facts recorded by the contemporaries; memorable signs.

In 2015, the student architects Maria Kobylina, Ekaterina Matel, Viktoria Ryabtseva and Pavel Yashchenko, who worked under the guidance of the Associate Professor of the Department of Architectural Design A.A. Lyapin, offered the residents of the Irkutsk region, the Russian and foreign tourists, their vision of solving the issue of developing modern recreational infrastructure. The "Green Trail" tourist health and educational enlightening greenway project was developed on the basis of the Institute of Architecture and Construction of Irkutsk National Research Technical University.

The main theme of the project dealt with the creation of a tourist-health greenway trail in the valley of the river. This type of planning recreational infrastructure is new for the Russian urban planning practice, and the development of such a project in the University has an innovative nature.

The "Green trail" is the greenway that is laid along the Kuda River, more than 25 kilometers long, from the village of Khomutovo and to the mouth of the Kuda River at the confluence of it into the Angara River. The route of the trail is laid by the already mentioned 
villages Urik and Ust-Kuda. The location of villages and respective location of the greenway trail are very successful in terms of transport accessibility. The village of Khomutovo is located near the Kachug tract, and the village of Urik stands on the Aleksandrovskii tract, 12 kilometers far from the village of Khomutovo. This part will be the first half of the greenway trail. The second half of the path will pass from the village of Urik to the mouth of the Kuda River on the Angara River, past the village of Ust-Kuda. Such distances are very convenient for organizing a one-day health-improving route for the residents of Irkutsk. The presence of the two main tracts will provide for flexibility in the use of the trail. The visitors of the greenway trail will be able to enter the trail or descend from it at three points: on the Kachug tract near the village of Khomutovo; on the Aleksandrovskii tract in the village of Urik, or at the mouth of the Kuda River on the side of the Angara River. Moreover, all three points are equidistant from Irkutsk by approximately 20 kilometers (Figure 3).

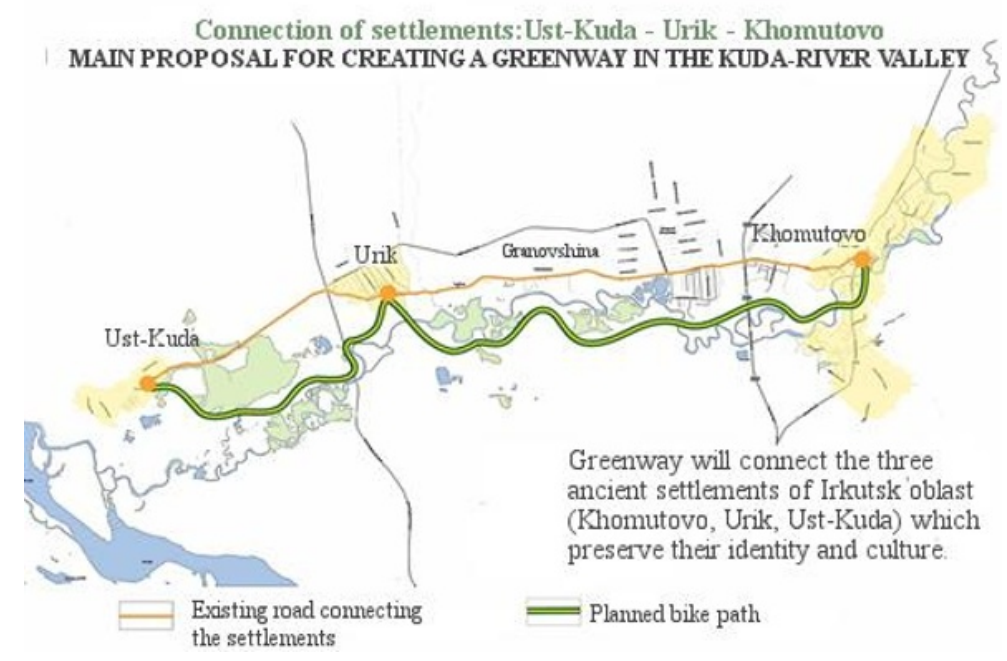

Fig. 3 Greenway project developed by the student architects Maria Kobylina, Ekaterina Matel, Viktoria Ryabtseva and Pavel Yashchenko under the guidance of the Associate Professor of the Department of Architectural Design A. A. Lyapin.

In addition to developing the main idea of the route, the design solutions for the stop points in the settlements were proposed in the project. In this case the settlements were considered as nodal points of the way, the same "beads" or thematic loops. The project stipulated for:

1. rectification of the roadway;

2. creating a comfortable environment for pedestrians;

3. shaping and formation of the main public space - a square near the temple;

4. landscape reconstruction and the organization of a hiking trail.

The organization and arrangement of the boulevard in the central part of the village of Urik became one of the main ideas of the project. The boulevard is intended for pedestrian traffic, from the park past the Church of the Savior to the square in front of the administration. The length of the boulevard is about $600 \mathrm{~m}$. A system of green plantations is proposed, which perform an important sanitary hygienic and architectural planning role. For recreation, small paved playgrounds with benches are to be located in the immediate vicinity of the church and administration that provide for a favorable view of the important elements in the planning of the village of Urik. 
In addition, it is proposed to create a small pine forest across the road for walking and resting both the local population and visiting guests. The park will partially continue the idea of the square - the tile gradually turns into a green massif and then into a pine forest.

Central parking for the administration of the village is proposed to be arranged behind the park. It will also provide parking for sixty parking spaces.

Near the church there is to be a round square and a multifunctional lawn for cultural recreation, folk festivities and other communicative purposes, which would fit into the unique landscape of the village without arguing with it. On the periphery of the square, groves are to be formed using both traditional tree species and ornamental abundantly flowering ones. Special attention was paid to the preservation of specific viewpoints looking at the church and the Kuda River. There is a descent into the valley of the river, which is proposed to be granted the status of the protected historical landscape. It also makes sense to recreate the fence of the church and restore the spruce grove on the north side, which will give solemnity by shading the dark silhouette of the greenery with the light silhouette of the church, and to organize parking for an average of 15 cars. Exit from the boulevard to the square and the pedestrian route to the educational institution is to be planted with greenery, and paving and landscaping are planned. It is proposed to organize a football field on the school grounds and increase the percentage of gardening.

The park zone is supposed to become the beginning of the "green path". The cycling and walking paths that pass here will periodically cross the river with wooden bridges. Near the bridges recreational areas for cyclists and barbecue areas are planned. It is proposed to arrange a low rarefied hedge along the road, and to arrange unregulated pedestrian crossings at the intersection with the tracks.

\section{Conclusion}

Greenways are not chosen by chance, as the most suitable environmental form of recreation functioning, filled with informative saturation.

On historical and cultural significance, we are dealing with the territory that has a high cultural potential due to a large number of historical and architectural monuments.

Objects not only possessing the status of the monument, so called material evidence of the developed space, but also those elements that belong to so called category of the intangible heritage can be included in the exposure system: the semantic, symbolic, spiritual and associative components of the landscape.

Applying the existing base of integrated assessment methods, it is possible to increase its significance for exposure by adopting the identified factors as an additional resource of the territory.

The properties of the landscape, which can be considered in connection with the inclusion of our territory in the recreational network, are the following: adaptability, integrity, authenticity, imagery, landscape, multilayered, and universality.

Creation of the system of view exposure of the most valuable landscape and cultural elements, with a representative presentation of the deep historical content, saturating the marking space with specially produced design additions in the form of plaques, memorials, signs, symbols, and thematic imitations will increase the investment attractiveness of this proposal and, accordingly, the economic effect of the implementation.

We believe that such a practice of involving unique resource of the territory in its recreational development will not only yield economic benefits, but also promote and raise the level of national awareness, spiritual and moral self-discipline, and rightfully contribute to the use of the principle of HERITAGE that is the main result of the research. 


\section{References}

5. $\quad$ N. G. Bubis, Urik, the village (2007)

6. N. G. Bubis, The Land of Irkutsk, 2(2), 8-12 (1994)

7. N. G. Bubis, Ust-Kuda - the red village (2007)

8. L. I. Gurova, "The Land of Irkutsk," 1(18), 54-55 (2002)

9. D. A. Dirin, A. S. Kuskov, The News of Altai State University, 3-1, 80-83 (2011)

10. I. V. Kalinina, Orthodox churches of the Irkutsk diocese, XVII - the beginning of the XX (Galart, Moscow, 2000)

11. I. V. Kalinina, The Land of Irkutsk, 2(2), 13-16 (1994)

12. A. A. Lyapin, Proceedings of the Irkutsk State Technical University, 10(93), 318-322 (2014)

13. A. A. Lyapin, Contemporary Landscape Design: New Perspectives: Proceedings of the International Scientific Conference, St. Petersburg, 102-104 (2010)

14. A. A. Lyapin, Project Baikal, 18, 58-59 (2008)

15. N. V. Shestopalova, E. V. Pulyaevskaya, Historical and Cultural Landscapes of Their Preservation and Development (IrNITU Publishing House, Irkutsk, 2012)

16. P. M. Shulgin, World of Russia, 2 (2004) 